\title{
Experiences With the University Admission Process and Educational Support Among Students With Cochlear Implants in South Korea
}

\author{
Young Sang Cho, ${ }^{1,2, *}$ (D) $\cdot$ Ga-Young Kim²,* (D) Hye Yoon Seol ${ }^{2}$ (D) $\cdot$ Eun Yeon $\mathrm{Kim}^{3}$ (D) $\cdot$ II Joon Moon ${ }^{1,2}$ (D) \\ ${ }^{1}$ Department of Otorhinolaryngology-Head and Neck Surgery, Samsung Medical Center, Sungkyunkwan University School of Medicine, Seoul; \\ ${ }^{2}$ Hearing Research Laboratory, Samsung Medical Center, Seoul; ${ }^{3}$ Department of Speech-Language Pathology, Myongji University, Seoul, Korea
}

Objectives. The aim of this study was to investigate the current university admission rate and experiences of educational support among students with cochlear implants (CIs) in South Korea.

Methods. A prospective online survey was conducted to examine the university admission process and academic support for students with CIs. Thirty individuals who took the college entrance exams at least 3 years after CI surgery were invited to participate, although two did not respond. The survey consisted of three topics (demographics, university admission process, and academic support) and 25 items regarding laws and policies related to university admission and support for students with hearing disabilities in Korea.

Results. The university matriculation rate for students with CI was $85.7 \%$ (24/28), of whom 50\% were admitted through the special admission process for students with disabilities. Most universities provided teaching and learning support and rental services for assistive devices for students with disabilities to help them better adapt to school life. However, only a small percentage of the students benefited from accommodation services, and $62.5 \%$ and $12.5 \%$ of the students received teaching and learning support and used assistive devices, respectively.

Conclusion. To the best of our knowledge, this is the first study to investigate the university admission process and university disability services for students with CIs in South Korea. The results of this study will be helpful for young CI recipients and their parents as they prepare for university entrance.

Keywords. Cochlear implants; Hearing Loss; Universities; Schools; Adolescent

\section{INTRODUCTION}

Cochlear implants (CIs) are effective auditory rehabilitation tools for patients with severe and profound hearing loss. Especially for infants with congenital deafness, $\mathrm{CI}$ is the only method of rehabilitation that allows them to hear and speak. In the late

\footnotetext{
- Received April 3, 2020

Revised September 15, 2020

Accepted September 24, 2020

- Corresponding author: Il Joon Moon

Department of Otorhinolaryngology-Head and Neck Surgery, Samsung

Medical Center, Sungkyunkwan University School of Medicine,

81 Irwon-ro, Gangnam-gu, Seoul 06351, Korea

Tel: +82-2-3410-3879, Fax: +82-2-3410-3579

E-mail: moonij@skku.edu

*These authors contributed equally to this work.
}

1970s, multichannel CIs were developed and many improvements were subsequently made in the 1980 s to 2000 s [1]. However, most $\mathrm{CI}$ recipients may still experience speech recognition difficulties in acoustically challenging environments. Specifically, the classroom is an environment that is acoustically and academically challenging for students due to several factors, such as the number of students per class, reverberation, the distance between the teacher and students, and the presence of internal or external background noise [2]. As a result, many CI recipients experience numerous difficulties in their academic and school life, and these problems are directly and indirectly linked to their experiences of university admission.

Most published research studies on children with CIs have focused on audition, speech, or language development $[3,4]$. Although these studies, typically conducted in laboratory settings,

Copyright @ 2021 by Korean Society of Otorhinolaryngology-Head and Neck Surgery.

This is an open-access article distributed under the terms of the Creative Commons Attribution Non-Commercial License (https://creativecommons.org/licenses/by-nc/4.0)

which permits unrestricted non-commercial use, distribution, and reproduction in any medium, provided the original work is properly cited. 
are very important, many children who receive CIs at a young age and their parents are interested in whether they can adapt well to school life and attend a good university or get a decent job. These issues are especially noteworthy in East Asian countries, where the "education fever" is quite high [5]. In particular, the interest in education in South Korea is especially high among the Organisation for Economic Co-operation and Development (OECD) countries [6].

In South Korea, nearly 12,000 CI procedures have been performed since the first CI was implanted in 1988. Since many of these recipients are pediatric patients, their needs during the college entrance process are becoming increasingly relevant, which has spurred significant changes in government policies for individuals with hearing disabilities. Since 1995, special admission guidelines for students with disabilities have broadened access to higher education for these individuals in South Korea. The university admission rate for students with disabilities increased from $5.2 \%$ in 1998 to $39.5 \%$ in 2017 [7]. Of 1,449 students with hearing loss, $1,018(70.2 \%)$ were reported to be receiving post-secondary education [7]. As such, there is a growing tendency among students with disabilities, including hearing loss, to attend university. However, to our knowledge, there have been no global or Korean studies of the academic achievements of CI patients, how they navigate the university admission process, and their adjustments to university. Therefore, this study sought to track the university admission process of patients who underwent $\mathrm{CI}$ surgery at a young age, to examine their current university life, and to identify any areas for improvement.

\section{MATERIALS AND METHODS}

\section{Participants}

Initially, a total of 30 individuals participated in this study from the outpatient clinic of the Department of Otolaryngology. Individuals who met the following eligibility criteria were included: students who underwent CI surgery between birth and 20 years of age, who have had CIs for more than 3 years, who have graduated from high school, and who had regularly visited the hospital for at least 3 years and received speech therapy. Study results were finally analyzed for 24 subjects, given four ultimately

\section{H I}

- Many cochlear implant (CI) recipients experience considerable difficulties in their academic and school life.

- We investigated the current university admission rate of students with CIs and their experiences of educational support.

- The results of this study will be helpful for young CI recipients and their parents as they prepare for university entrance. did not enter university and two did not complete the study questionnaire. Demographic characteristics are shown in Table 1. The type of deafness was classified into "pre-lingual" (16/24, $66.7 \%)$ and "post-lingual" (8/24, 33.3\%) based on whether the hearing loss occurred before or after the acquisition of language. The auditory performance was calculated from the average pure-tone audiometry at 500,1,000, 2,000, and 4,000 Hz.

\section{Procedure}

An online survey was conducted to examine the university admission process and academic support for students with CIs. The survey consisted of three topics (demographics, university admission process, and academic support) and 25 items regarding laws and policies related to university admission and educational support for students with disabilities in Korea.The address for the survey was texted to those who agreed to participate in the study.This study was approved by the Institutional Review Board at Samsung Medical Center in Seoul, South Korea in accordance with the Declaration of Helsinki (IRB No. 2019-11-037).

\section{Statistical analysis}

Demographics and academic support measures were summarized with descriptive statistics. In the university admission process topics, chi-square test was performed to identify significant differences in frequencies between the pre- and post-lingual deafness groups.

\section{RESULTS}

\section{University admissions for students with Cls}

The university acceptance rate for students with CIs was $85.7 \%$ (24/28). Nine (37.5\%) proceeded to enter a 2-year college program, while $15(62.5 \%)$ enrolled in a 4-year college program. Furthermore, $50 \%(12 / 24)$ of the accepted participants were admitted under special admission rules for students with disabilities (Table 2), while nine respondents (37.5\%) were admitted by way of nonscheduled admission. Humanities and social sciences $(10 / 24,41.7 \%)$ were the most commonly chosen majors. The main reason for participants' selection of their majors was "I was interested in my major" (54.2\%). At the time of enrollment, only one person was required to choose his or her major because of the special admission process. Communication was not an issue, as none of the participants determined their firstchoice major based on whether or not it facilitated communication. However, seven students $(29.2 \%)$ considered changing their major and two of them responded that it was due to communication problems (Supplementary Table 1). According to the chisquare test, there were no significant differences between the pre- and post-lingual deafness groups in any of the variables related to the university admission process (Table 2, Supplementary Table 1). 


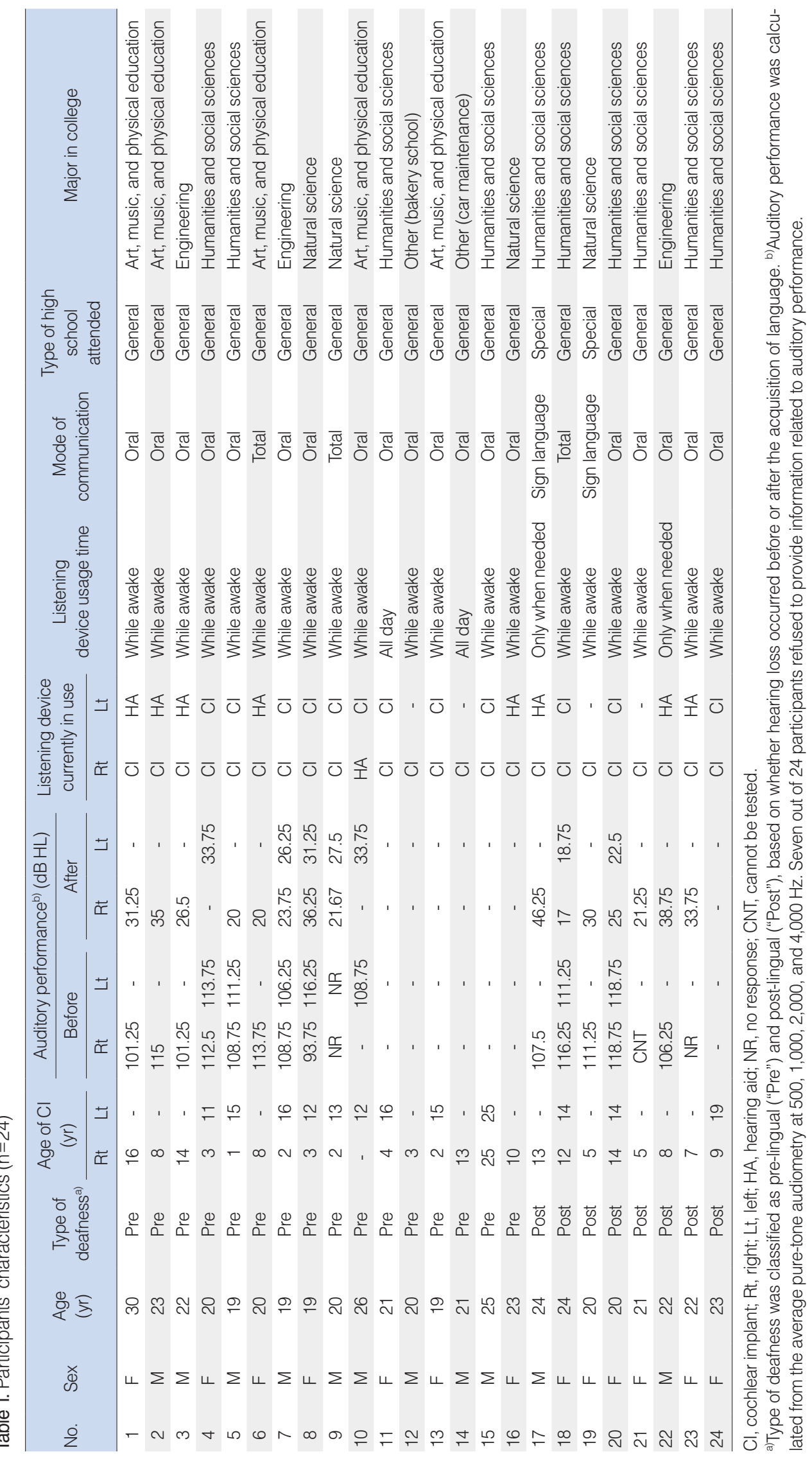


Table 2. Type of university admission process, type of university, and major $(n=24)$

\begin{tabular}{|c|c|c|c|c|}
\hline Item & Pre-lingual $(n=16)$ & Post-lingual $(n=8)$ & Total $(n=24)$ & $P$-value \\
\hline Type of admission process & & & & 0.275 \\
\hline Regular admission & $1(6.3)$ & 0 & $1(4.2)$ & \\
\hline Nonscheduled admission & $4(25.0)$ & $5(62.5)$ & $9(37.5)$ & \\
\hline Special admission for students with disabilities & $9(56.3)$ & $3(37.5)$ & $12(50.0)$ & \\
\hline Other & $2(12.5)$ & 0 & $2(8.3)$ & \\
\hline Type of university & & & & 0.371 \\
\hline Two-year program & $5(31.3)$ & $4(50.0)$ & $9(37.5)$ & \\
\hline Four-year program & $11(68.8)$ & $4(50.0)$ & $15(62.5)$ & \\
\hline Major & & & & 0.145 \\
\hline Humanities and social sciences & $4(25.0)$ & $6(75.0)$ & $10(41.7)$ & \\
\hline Natural science & $3(18.8)$ & $1(12.5)$ & $4(16.7)$ & \\
\hline Art, music, and physical education & $5(31.3)$ & 0 & $5(20.8)$ & \\
\hline Engineering & $2(12.5)$ & $1(12.5)$ & $3(12.5)$ & \\
\hline Medicine and public health & 0 & 0 & 0 & \\
\hline Other & $2(12.5)$ & 0 & $2(8.3)$ & \\
\hline
\end{tabular}

Values are presented as number (\%).

Table 3. Availability of and experiences with centers for disability services ( $n=24)$

\begin{tabular}{|c|c|c|}
\hline Item & Response & No. $(\%)$ \\
\hline \multirow[t]{3}{*}{ Availability of center for disability services } & Yes & $19(79.2)$ \\
\hline & No & $3(12.5)$ \\
\hline & Don't know & $2(8.3)$ \\
\hline \multirow[t]{13}{*}{ Experiences with center for disability services } & Yes & $13(54.2)$ \\
\hline & Notification from the school & $8(61.5)$ \\
\hline & Searched for information on their own & $1(7.7)$ \\
\hline & Heard about it from nondisabled students & 0 \\
\hline & Heard about it from other students with hearing loss & $3(23.1)$ \\
\hline & Other & $1(7.7)$ \\
\hline & No & $11(45.8)$ \\
\hline & I didn't know whether such a center existed at my university. & $6(54.5)$ \\
\hline & They didn't have programs that I wanted. & $1(9.1)$ \\
\hline & The program offered by the center wouldn't help me. & $3(27.3)$ \\
\hline & The workers at the center were rude to me. & 0 \\
\hline & I didn't want friends to know that I used a center. & $1(9.1)$ \\
\hline & Other & 0 \\
\hline
\end{tabular}

\section{Academic support for students with Cls}

With regard to the availability of the center for disability services at each university, 19 of the $24(79.2 \%)$ participants responded that the center was located at their university and $13(54.2 \%)$ had visited the facility by the time of the survey. When students were asked about how they received information about the center, the most common response was "notification from the school" (61.5\%), followed by "heard about it from other students with hearing loss" (23.1\%), "searched for information on their own" (7.7\%), and other $(7.7 \%)$. The most common reason for not using the center was "I didn't know whether such a center existed at my university" (54.5\%) (Table 3).

Regarding available teaching and learning support, 21 participants $(87.5 \%)$ responded that assistant services were available at their university and $15(62.5 \%)$ had first-hand experiences with those services. One of the most frequently used services was class assistance (e.g., note-taking) (73.3\%). The most frequent reason for not using assistant services was "I didn't know whether assistant services were available at my university" $(33.3 \%)$ (Table 4). Students with hearing loss considered speech-to-text translation to be the most important assistant service, followed by class assistance, shorthand, and sign language interpretation (Supplementary Table 2).

Thirteen participants $(54.2 \%)$ mentioned that assistive device rental services were offered through their university, while nine (37.5\%) did not know whether or not such services were available. This service was mainly not used by students because most of them answered that "they didn't know whether a rental service for assistive devices was available at the university" (55\%) (Table 5). 
Table 4. Availability of and experiences with assistant services $(n=24)$

\begin{tabular}{|c|c|c|}
\hline Item & Response & No. (\%) \\
\hline \multirow[t]{3}{*}{ Availability of assistant services } & Yes & $21(87.5)$ \\
\hline & No & $1(4.2)$ \\
\hline & Don't know & $2(8.3)$ \\
\hline \multirow[t]{12}{*}{ Experiences with assistant services } & $Y_{e s}{ }^{a)}$ & $15(62.5)$ \\
\hline & Sign language interpretation & $1(6.7)$ \\
\hline & Text interpretation & $3(20)$ \\
\hline & Shorthand & $5(33.3)$ \\
\hline & Class assistance (e.g., taking notes) & $11(73.3)$ \\
\hline & Other & 0 \\
\hline & $\mathrm{No}^{\mathrm{a})}$ & $9(37.5)$ \\
\hline & I didn't know whether assistant services were available at my university. & $3(33.3)$ \\
\hline & They didn't have services that I wanted. & $2(22.2)$ \\
\hline & The assistant service wouldn't help me. & $2(22.2)$ \\
\hline & I didn't want friends to know that I used a service. & $2(22.2)$ \\
\hline & Other & 0 \\
\hline
\end{tabular}

a)The total percentage could exceed $100 \%$ because of multiple answers.

Table 5. Availability of and experiences with rental services for assistive devices $(n=24)$

\begin{tabular}{|c|c|c|}
\hline Item & Response & No. (\%) \\
\hline \multirow[t]{3}{*}{ Availability of rental service for assistive devices } & Yes & $13(54.2)$ \\
\hline & No & $2(8.3)$ \\
\hline & Don't know & $9(37.5)$ \\
\hline \multirow[t]{12}{*}{ Experiences with rental service for assistive devices } & $Y_{e s}{ }^{a)}$ & $4(16.7)$ \\
\hline & Laptop computer & $2(50.0)$ \\
\hline & Recorder & 0 \\
\hline & Camera (camcorder) & 0 \\
\hline & FM system & $2(50.0)$ \\
\hline & Other & 0 \\
\hline & $\mathrm{No}^{\mathrm{a})}$ & $20(83.3)$ \\
\hline & $\begin{array}{l}\text { I didn't know whether a rental service for assistive devices was available at } \\
\text { my university. }\end{array}$ & $11(55.0)$ \\
\hline & They didn't have services that I wanted. & $4(20.0)$ \\
\hline & The assistant service wouldn't help me. & $3(15.0)$ \\
\hline & I didn't want friends to know that I used a service. & $1(5.0)$ \\
\hline & Other & $1(5.0)$ \\
\hline
\end{tabular}

a)The total percentage could exceed $100 \%$ because of multiple answers.

Students needed assistance most often for listening to lectures, followed by during presentations, group projects, or personal projects (Supplementary Table 3). When asked about the helpfulness of the support system provided by the institution for their academic life, $54.5 \%$ responded that it was moderately helpful.

\section{DISCUSSION}

The history of laws on education for students with disabilities in Korea is quite short. In 1995, the special university admissions system for individuals with special needs was first introduced. The enforcement decree of the Higher Education Act was announced in 1998 and special education laws for those with dis- abilities were enacted in 2007. In 1995, the number of students with disabilities totaled only 113 across eight universities. In comparison, in 2015, 1,377 students were enrolled at 116 universities, representing a more than 10 -fold increase in the population within 20 years. The 2014 statistical report of Statistics Korea reported that the rates of tertiary education institution entrance among the general population and those with disabilities were $68.9 \%$ and $46.3 \%$, respectively [8]. This suggests that the absolute number of people with disabilities attending university has significantly increased, likely as a result of the aforementioned legislation and government efforts, but further efforts are still needed.

Among the various types of disabilities, the university entrance rate of people with hearing impairment is $70.3 \%$, which is some- 
what higher than the rates of people with other disabilities (e.g., visual, developmental disability, autism). This is thought to be due to the possibility of attaining sufficient hearing rehabilitation through the use of hearing aids or CIs, whereas other disabilities may not be as readily treatable. In our study, 22 of 24 participants $(91.7 \%)$ attended regular high schools, and only two $(8.3 \%)$ attended a special school. This finding is consistent with the results of Bae et al. [9], who found that the number of students with hearing impairments in mainstream classes tended to be higher than that of students with other disorders. In particular, CI users were found in mainstream classes in significant numbers. One study showed that 61 of 67 (91\%) prelingual deaf children with CIs attended ordinary classes in a mainstream school [10].

Many studies have been conducted on the long-term academic outcomes of school-aged children with CIs and explored their educational performance. Mukari et al. [11] reported the educational accomplishments in a mainstream class of 20 prelingual deaf patients, and found that $56.25 \%$ of them achieved belowaverage performance. Sarant et al. [12] compared the academic performance of individuals with normal hearing and patients with bilateral and unilateral CIs; on average, the academic outcomes of all $\mathrm{CI}$ users were poorer than those with normal hearing, but the authors further concluded that using CIs in both ears at younger ages could lead to better academic outcomes among children with severe to profound hearing loss [12]. Unlike previous research, Choi et al. [10] reported that half of prelingual deaf children with CIs scored above average in terms of general academic performance. However, the children with CIs had lower levels of achievement in second language learning (English), social studies, and science because of difficulties in understanding complex verbal explanations. In addition, a number of studies have analyzed outcomes related to educational, psychosocial, functional, and communicative aspects in CI patients, but few investigations have sought to elucidate these individuals' academic progress including university admission and adaptation to university life. Spencer et al. [13] found that $75 \%$ (12/16) of CI patients attended post-high school institutions, of whom seven attended universities and five attended community colleges.

South Korea's educational level is the highest in the world. According to the OECD Education Index 2019 released by the Ministry of Education in September of this year, the rate of completion of tertiary education among Korean youth was $69.6 \%$, marking the 10th straight year that South Korea has been in first place among OECD countries [14]. Children with CIs and their parents are also very interested in higher education. Therefore, it is meaningful to understand the university entrance process experienced by students with CIs and to investigate their actual university life in general. The present study found that $91.7 \%$ of study participants had attended regular high schools, with only one graduating from a specialized high school. Among them, $85.7 \%$ went to a university and $62.5 \%$ specifically attended 4-year universities, showing a fairly high level of education. Additionally, $50 \%$ of students were admitted through the special admission process for students with disabilities, and the government policies for individuals with disabilities and the efforts of each university suggest that relatively good results pertaining to the inclusion of students with disabilities are being achieved. When analyzing pre-/post-lingual deafness, participants with post-lingual deafness had a relatively high rate of choosing majors in the humanities and social sciences, while participants with pre-lingual deafness tended to choose majors in the category of art, music, and physical education, but this difference was not statistically significant. The students with prelingual deafness also tended to use the special admission system for students with disabilities, but this difference was likewise not statistically significant.

The assistant and assistive device rental services for students with disabilities were relatively well-established at each university, but only $62.5 \%$ of the participants reported using these services, and $12.5 \%$ of the respondents said that the system was beneficial to them. This finding demonstrates that more efforts still need to be made to investigate the types of support that students with hearing loss really need and to provide the necessary support.

The limitations of this study include the small number of participants and the fact that the survey participants were more likely to have embarked upon a higher education program than those who did not respond. Therefore, multicenter studies should be conducted in the future with more CI patients at various facilities. In addition, some of the patients participating in this study received surgery at other hospitals, or after examination at other hospitals, followed by surgery and speech therapy at our medical center; therefore, the hearing outcomes of some patients before and after surgery could not be included. However, the impact of this limitation is not substantial, since the focus of this study was on current communication skills and types, rather than objective hearing outcomes. Lastly, the results of this study may have been influenced by parental academic status, household income, and region of residence, but the present study did not analyze these factors.

The first CI operation was performed in Korea in 1988 and the procedure became quite popular around 2001. Since then, 18 years have passed; therefore, patients who underwent CI surgery around the age of 1 year are now ready to enter university after graduating from high school, and the number of these patients is only expected to increase in the future. For this reason, further research and analysis of the university admission process and academic life of CI patients will be meaningful. This study provides valuable information for young $\mathrm{CI}$ patients and their parents. In conclusion, The results of this study will be helpful for young CI recipients and their parents as they prepare for university entrance. 


\section{CONFLICT OF INTEREST}

No potential conflict of interest relevant to this article was reported.

\section{ORCID}

Young Sang Cho

Ga-Young Kim

https://orcid.org/0000-0002-4040-7206

Hye Yoon Seol

https://orcid.org/0000-0002-8945-4927

https://orcid.org/0000-0002-7040-1884

Eun Yeon Kim

https://orcid.org/0000-0002-7382-6271

Il Joon Moon

\section{AUTHOR CONTRIBUTIONS}

Conceptualization: YSC, GYK, IJM. Data curation: YSC, GYK. Formal analysis: HYS, EYK. Project administration: EYK, IJM. Writing-original draft:YSC, GYK.Writing-review \& editing:YSC, GYK, EYK, IJM.

\section{SUPPLEMENTARY MATERIALS}

Supplementary materials can be found via https://doi.org/10. 21053/ceo.2020.00535.

\section{REFERENCES}

1. Eshraghi AA, Nazarian R, Telischi FF, Rajguru SM, Truy E, Gupta C. The cochlear implant: historical aspects and future prospects. Anat Rec (Hoboken). 2012 Nov;295(11):1967-80.

2. Davies M, Yellon L, Purdy S. Speech-in-noise perception of children using cochlear implants and FM systems. Aust N Z J Audiol. 2001 May;23(1):52-62.

3. Punch R, Hyde MB. Communication, psychosocial, and educational outcomes of children with cochlear implants and challenges remaining for professionals and parents. Int J Otolaryngol. 2011;2011: 573280.

4. Debruyne JA, Janssen AM, Brokx JP. Systematic review on late cochlear implantation in early-deafened adults and adolescents: clinical effectiveness. Ear Hear. 2020 Nov/Dec;41(6):1417-30.

5. Ashitani M, Ueno C, Doi T, Kinoshita T, Tomoda K. Clinical features of functional hearing loss with inattention problem in Japanese children. Int J Pediatr Otorhinolaryngol. 2011 Nov;75(11):1431-5.

6. Lee CJ. Korean education fever and private tutoring. Kedi J Educ Policy. 2005;2(1):99-107.

7. Yoon JW, Kwon ME, Kim RK, Seo YJ, Son CK, Lee GS, et al. 2017 Report on special education services in Korea. Seoul: Korea National Institute for Special Education; 2017.

8. Korean Statistical Information Service (KOSIS). Career direction after high school graduation [Internet]. Daejeon: KOSIS; 2016 [cited 2020 Nov 12]. Available from: http://kosis.kr/statHtml/statHtml.do? mode=tab\&orgId=112\&tblId=DT_11214_2014A024\&vw_cd=MT_ ZTITLE\&list_id=112_11214_300_A1\&scrId=\&seqNo=\&lang_mode= ko\&obj_var_id=\&itm_id=\&conn_path=MT_ZTITLE\&path $=\% 252 \mathrm{~F}$ statisticsList\%252FstatisticsListIndex.do.

9. Bae SH, Kwak SH, Nam GS, Choi JY. Educational status in bilateral prelingual deaf children with cochlear implantation. J Audiol Otol. 2019 Jul;23(3):135-9.

10. Choi JE, Hong SH, Moon IJ.Academic performance, communication, and psychosocial development of prelingual deaf children with cochlear implants in mainstream schools. J Audiol Otol. 2020 Apr;24(2): 61-70.

11. Mukari SZ, Ling LN, Ghani HA. Educational performance of pediatric cochlear implant recipients in mainstream classes. Int J Pediatr Otorhinolaryngol. 2007 Feb;71(2):231-40.

12. Sarant JZ, Harris DC, Bennet LA. Academic outcomes for schoolaged children with severe-profound hearing loss and early unilateral and bilateral cochlear implants. J Speech Lang Hear Res. 2015 Jun; 58(3):1017-32.

13. Spencer LJ, Tomblin JB, Gantz BJ. Growing up with a cochlear implant: education, vocation, and affiliation. J Deaf Stud Deaf Educ. 2012 Fall;17(4):483-98.

14. Ministry of Education. 2019 Educational statistics of OECD [Internet]. Seoul: Ministry of Education; 2019 [cited 2020 Nov 12]. Available from: https://www.moe.go.kr/boardCnts/view.do?boardID=29 $4 \& l e v=0 \&$ status $\mathrm{YN}=\mathrm{W} \& \mathrm{~s}=\mathrm{moe} \& \mathrm{~m}=0204 \&$ opType $=\mathrm{N} \&$ boardS eq $=78485$. 